\title{
HETEROSPERMIC INSEMINATION OF RABBIT SEMEN AS A MEANS OF EVALUATING TECHNIQUES OF SEMEN HANDLING
}

\author{
P. J. O'REILLY,* G. N. GRAVES $\dagger$ AND P. J. DZIUK \\ Departments of Animal Science and $\nmid$ Dairy Science, University of Illinois, \\ Urbana, Illinois 61801, U.S.A.
}

(Received 26th March 1971, accepted 24th May 1971)

Summary. The comparative efficiency of two semen extenders, eggyolk-Illini Variable Temperature extender (E) and reconstituted milk $(\mathrm{M})$, in the maintenance of fertilizing ability was tested by heterospermic insemination using semen from Black (B) and White (W) males whose offspring were distinguishable. Semen from the different males was combined just before insemination to give a mixture of equal numbers of spermatozoa from each. Each of the male/semen combinations $\mathrm{BE}+$ $\mathrm{WE}, \mathrm{BM}+\mathrm{WM}, \mathrm{BE}+\mathrm{WM}$ and $\mathrm{BM}+\mathrm{WE}$ was inseminated into one of four groups of females.

There were no significant differences between groups in the proportion of does kindling or in litter size. When the BE +WE combination was used, $69 \%$ of progeny were $\mathrm{W}$ and when the $\mathrm{BM}+\mathrm{WM}$ combination was used, $86 \%$ were $\mathrm{W}$. When the $\mathrm{BM}+\mathrm{WE}$ combination was inseminated, $96 \%$ of progeny were $\mathrm{W}$. However, when $\mathrm{BE}+\mathrm{WM}$ was used, only $32 \%$ of progeny were W. Spermatozoa stored in E were associated with a significantly greater proportion of offspring than spermatozoa from males stored in $M$ when $B E$ was compared with WM ( $P$ $<0.001)$ and when WE was compared with WM $(P<0.01)$. It is concluded that the competitive advantage enjoyed by spermatozoa stored in $E$ is due to the superiority of the $E$ extender in maintaining fertilizing ability. This finding suggests that appropriate heterospermic inseminations could be used to distinguish between semen handling techniques and extenders.

\section{INTRODUGTION}

When spermatozoa from two or more fertile males are mixed and inseminated in equal numbers, the ratio of the resulting progeny of this heterospermic, competitive insemination is often unequal. The predominance in the proportion of resulting progeny of one male over another is consistent and reproducible (Edwards, 1955; Beatty, 1957, 1960). Heterospermic predominance of males has been established between strains as well as between individuals within strains (Edwards, 1955).

* Present address: A. I. Research Station, Ballycoolin Road, Finglas, Dublin 11, Ireland. 
The male which is predominant heterospermically also tends to have a relatively higher fertility than his competitors when used homospermically (Beatty, 1960; Beatty, Bennett, Hall, Hancock \& Stewart, 1969). An index of fertility based on heterospermic predominance was found by Beatty et al. (1969) to be a more sensitive measure than one based on the percentage of cows returning to oestrus. Differences between the fertilizing ability of spermatozoa following different storage periods were easily detected by heterospermic inseminations that were not detectable by the usual methods of comparing conception rates and litter sizes (Roche, Dziuk \& Lodge, 1968). The following experiment, using two semen extenders, was conducted to test the hypothesis that, if heterospermicinsemination can be used efficiently to measure the relative fertility of males and the effect of storage period on fertility, it can also be used to distinguish between the relative merits of various ways of preserving spermatozoa.

\section{MATERIALS AND METHODS}

One semen extender (E) consisted of the Illini Variable Temperature diluent containing $20 \%$ egg yolk (VanDemark \& Sharma, 1957) but containing sulphanilamide only, as a bacteriostat. The second extender (M) consisted of $9 \cdot 6 \mathrm{~g}$ dried milk powder (Carnation Nonfat Powder) reconstituted in $100 \mathrm{ml}$ distilled water containing $0.3 \mathrm{~g}$ sulphanilamide. Thereafter, it was heated to $92^{\circ} \mathrm{C}$ for $2 \mathrm{~min}$ and allowed to cool to room temperature.

\begin{tabular}{|c|c|c|c|}
\hline \multicolumn{4}{|c|}{ TABLE 1} \\
\hline COMBII & IATIONS OF & BUCKS & AND \\
\hline \multicolumn{4}{|c|}{ EXTENDERS } \\
\hline \multirow[b]{2}{*}{ Group } & \multicolumn{3}{|c|}{ Combination as inseminated } \\
\hline & $\begin{array}{c}\text { As stored } \\
\text { Male Extender }\end{array}$ & \multicolumn{2}{|c|}{$\begin{array}{c}\text { As stored } \\
\text { Male Extender }\end{array}$} \\
\hline $\begin{array}{l}1 \\
2 \\
3 \\
4\end{array}$ & $\begin{array}{ll}\mathbf{B} & \mathbf{E} \\
\mathbf{B} & \mathbf{M} \\
\mathbf{B} & \mathbf{E} \\
\mathbf{B} & \mathbf{M}\end{array}$ & $\begin{array}{l}\mathbf{W} \\
\mathbf{W} \\
\mathbf{W} \\
\mathbf{W}\end{array}$ & $\begin{array}{l}\mathbf{E} \\
\mathbf{M} \\
\mathbf{M} \\
\mathbf{E}\end{array}$ \\
\hline- & 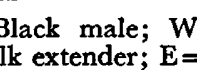 & & \\
\hline
\end{tabular}

Semen from two New Zealand White (W) and two Dutch Belted Black (B) bucks was collected using an artificial vagina. The sperm concentration was determined using a Neubauer haemocytometer. Semen from males of the same colour was mixed and redivided into two equal parts. Each sample was adjusted so as to contain $50 \times 10^{6}$ spermatozoa $/ \mathrm{ml}$ in either $\mathrm{E}$ or $\mathrm{M}$ and was then stored at $4^{\circ} \mathrm{C}$ for $48 \mathrm{hr}$. The sperm motility of each sample was estimated microscopically before and after storage but motility was not used as a basis for establishing the proportions of spermatozoa in mixed samples. Just before insemination, the diluted samples were mixed in equal volumes to produce four 
different combinations, each containing spermatozoa from both $\mathrm{B}$ and $\mathrm{W}$ males as shown in Table 1.

New Zealand White does were identified individually and allocated randomly into four groups of twenty-three does each to correspond with the four semen combinations for a total of ninety-two inseminations. At the time of insemination, each doe was injected intravenously with 50 i.u. HCG in 0.25 $\mathrm{ml}$ to induce ovulation and was inseminated with $0.3 \mathrm{ml}$ of one of the semen combinations containing $16 \times 10^{6}$ spermatozoa.

At the time of parturition, the does were inspected frequently and the number and colour of the progeny were recorded. Differences between groups in litter size, in proportions kindling and between ratios of offspring within groups were analysed by chi-square. Differences between ratios of offspring were analysed by analysis of variance following angular transformation.

\section{RESULTS}

Three hundred and seven progeny were produced from fifty-one of the ninetytwo inseminations for a parturition rate of $55 \%$ with a litter size ranging from one to eleven and a mean of six (Table 2). There were no statistical differences

\section{TABLE 2}

FERTILITY AND PERGENTAGE OF PROGENY RESULTING WHEN SEMEN FROM BLACK AND WHITE BUGKS WAS STORED IN TWO DIFFERENT EXTENDERS FOR 48 HR AT $4^{\circ} \mathrm{C}$

\begin{tabular}{l|c|c|c|c}
\hline & \multicolumn{4}{|c}{ Male-extender combinations } \\
\cline { 2 - 5 } & $B E+W E$ & $B M+W M$ & $B M+W E$ & $B E+W M$ \\
& 1 & 2 & 3 & 4 \\
\hline No. of litters & 14 & 12 & 11 & 14 \\
Does pregnant (\%) & 61 & 52 & 48 & 61 \\
Progeny & 98 & 69 & 55 & \\
$\quad$ No. & 7 & $5 \cdot 7$ & $5 \cdot 0$ & 65 \\
Per litter & 69 & 87 & 96 & 32 \\
$\%$ W & & & & \\
\hline
\end{tabular}

B = black; $W=$ White; $E=$ Egg; $M=$ Milk.

1. A significantly greater proportion of $W$ offspring were produced in Groups 1 and 3 combined than in Groups 2 and 4 combined, $P<0.01$.

2. A significantly greater proportion of $\mathbf{B}$ offspring were produced in Groups 1 and 4 combined than in Groups 2 and 3 combined, $P<0.001$.

3. Significantly more than $50 \%$ of the progeny were $W$ in Groups 1,2 and 3 and significantly more than $50 \%$ were $B$ in Group $4, P<0.001$.

4. No significant difference between groups in $\%$ pregnant or number of progeny/litter, $P<0.05$.

between groups in the proportion of does kindling or in litter size $(P<0.05)$. Seven litters were only $B$, twenty-three were only $W$ and twenty-one had both $\mathrm{B}$ and $\mathrm{W}$ members. There were $208 \mathrm{~W}$, and ninety-nine $\mathrm{B}$ progeny. Two hundred and nine progeny were born from spermatozoa stored in $\mathrm{E}$ as opposed to ninety-eight from spermatozoa stored in $\mathbf{M}$. Significantly more progeny were produced from spermatozoa stored in $\mathrm{E}$ than $\mathrm{M}$ when WE was compared with 
WM $(\mathbf{P}<0 \cdot 01)$. Likewise, there were significantly more progeny from spermatozoa stored in $\mathrm{E}$ when $\mathrm{BE}$ was compared with BM $(P<0 \cdot 001)$. No significant interaction between $\mathbf{M}$ and $\mathbf{E}$ could be detected on analysis.

\section{DISGUSSION}

The proportion of progeny sired by $\mathrm{B}$ and $\mathrm{W}$ males, following heterospermic insemination in this experiment, has been used as a measure of (1) the comparative ability of two extenders to maintain competitive fertilizing ability of spermatozoa and (2) heterospermic predominance of the males.

When the results were analysed by the usual estimates of fertility such as pregnancy rate and litter size between Groups 1 and 2, no differences between groups could be detected. In this non-competitive situation, spermatozoa stored in $M$ were able to fertilize eggs at a rate not statistically significantly lower than spermatozoa stored in E. However, analysis of the proportion of W progeny resulting when semen from the $W$ male was stored in $E$ and $M$ showed that spermatozoa stored in $\mathbf{E}$ were more likely to fertilize eggs than spermatozoa stored in $\mathrm{M}(P<0 \cdot 01)$. A greater statistical significance in favour of $\mathrm{E}$ was obtained $(P<0.001)$ when an analysis was made of the proportion of progeny resulting from storing $B$ spermatozoa in $E$ than in $M$. It is concluded that as measured in this experiment, $\mathrm{E}$ is superior to $\mathrm{M}$ for preserving the competitive fertilizing ability of rabbit spermatozoa.

The advantage imparted to spermatozoa stored in $\mathbf{E}$ is emphasized when one considers that $\mathrm{W}$ males were able to sire $96 \%$ of the progeny when their spermatozoa were stored in $\mathrm{E}$ in competition with spermatozoa from $\mathrm{B}$ males stored in $\mathrm{M}$ (Group 3), but were able to sire only $32 \%$ of the progeny when their spermatozoa stored in $\mathbf{M}$ had to compete against B spermatozoa stored in E (Group 4). The fact that the predominant male in heterospermic inseminations has also been shown (Beatty, 1960; Beatty et al., 1969) to have a relatively higher fertility in homospermic inseminations suggests that $\mathrm{E}$ would maintain a higher fertilizing ability of spermatozoa than $\mathrm{M}$ in non-competitive homospermic inseminations under the same conditions.

Usually the comparison of two or more semen treatments is made by analysing the differences between the percentages of inseminated animals producing progeny or the percentages of animals that have not been observed in oestrus by a certain interval after insemination. Both these measures of conception are fraught with many potential errors such as variation in inseminator efficiency from time to time and between individuals, variation in level of female fertility, occurrence of oestrus in pregnant animals and failure to show or detect oestrus in non-pregnant animals, and the difficulty in assembling significant quantities of reliable data (Salisbury \& VanDemark, 1961). Heterospermic inseminations either eliminate or reduce the effect of these variables.

Because each spermatozoon in an inseminate has a theoretically equal chance to fertilize an egg in any one female, the competence of the inseminator or the relative fertility of the female is unlikely to favour one spermatozoon over another. Only those offspring born are included in the data which are considered in proportions so that the relative level of fertility resulting from the 
treatment has no influence on the outcome, whether it be low or high and regardless of whether it is due to low fertility of the inseminated females or a drastic semen treatment.

Salisbury \& VanDemark (1961) calculated that at least 300 homospermic inseminations were required to reduce the standard deviation to $2.8 \%$. A similar estimate (Dunn, Henderson \& Godfrey, 1956) showed that when the difference between two groups in non-return rate was $10 \%, 500$ inseminations were required to show a statistically significant difference with a $95 \%$ probability confidence level. In the present experiment with fifty-one fertile inseminations and 307 progeny, the differences between Group $1(B E+W E)$ and Group 2 $(\mathrm{BM}+\mathrm{WM})$ in kindling rates were not significant but by appropriate heterospermic inseminations and analysis, differences between the effect of $E$ and $M$ were readily apparent and statistically significant. Comparisons between treatments could then be made quite adequately with greater sensitivity and confidence with relatively fewer heterospermic inseminations than is now the case with homospermic inseminations.

The system could be expanded so that more than two semen treatments could be compared. The additional treatments would require that progeny from additional sires could be identified by genetic markers such as colour or blood type. Thus, semen from several males could be mixed in one inseminate with several different treatments applied to the semen. In comparing treatments of bull semen, fertility would be increased as the number of sires contributing to the inseminate increased (Beatty, 1960). Such experimentation would be acceptable to those cattle owners who are interested primarily in a high calving rate regardless of the genetic constitution of the calf. This would permit simultaneous assessment of the relative fertilizing ability of sires as well as the relative value of semen treatments.

The experimental model presented here applies not only to the comparative evaluation of extenders but also has potential application to the assessment of the efficacy of different extender constituents, and handling procedures for semen, such as the rate of cooling, the temperature and rate of glycerolization, equilibration time, and methods of packaging and freezing. The methods used for handling and storage of semen may alter the rate of maturation and ageing of spermatozoa which, in turn, may affect the optimum time between insemination and ovulation to achieve maximum fertility. Heterospermic inseminations may also be applied to determine the optimum time for insemination under specific conditions (Dziuk, 1970).

The results indicate that, when equal numbers of spermatozoa from each male were stored in the same extender (Groups 1 and 2, Table 2), the W males were predominant. The proportion of $\mathrm{W}$ progeny was even greater when spermatozoa of both males were stored in $M$ than when both were in $E$, indicating that storage of semen in $\mathbf{M}$ accentuated the advantage of $\mathrm{W}$ males. There may have been an unequal dilution shock between semen samples from $\mathrm{B}$ males as compared with $\mathrm{W}$ males due to differences in sperm concentration in the ejaculate. However, if an unequal dilution shock did occur, its effect was masked by the overriding effect of the extender and would, therefore, not change the interpretation of this experiment. 
The semen from two males of one colour was mixed and used as one sample. One of the males of the same colour may have predominated over the other. This presumably would reduce the sensitivity of the comparison of the present experiment as opposed to a similar experiment using only one B male and one W male.

The causes of heterospermic predominance have been explained by factors known to alter sire predominance. The predominant sire may become subordinate if the proportion of his spermatozoa in the inseminate is reduced (Beatty, 1957); thus, it has been proposed that the predominant sire is predominant because he has relatively more live spermatozoa (Beatty et al., 1969). Whether a sire is predominant or not can also be altered by varying the interval from mating to ovulation. This phenomenon may be explained on the basis of the rate of maturation of spermatozoa within the female tract (Dziuk, 1965).

The level of fertility of spermatozoa increases as they pass through the epididymis (Orgebin-Crist, 1968). This culminates in maximum fertility being achieved approximately $12 \mathrm{hr}$ after deposition of spermatozoa within the female tract or storage in vitro (Dziuk, 1965; Salisbury, 1965; Miller, Roche \& Dziuk, 1969; Dziuk, 1970). Thus, heterospermic predominance could be due to the relative maturity of the spermatozoa at the time of fertilization. Males ejaculating immature, over-mature or slowly maturing spermatozoa would have little chance of siring progeny when put in competition with males whose spermatozoa matured at the optimum time relative to ovulation, unless the period between ejaculation and ovulation were altered in favour of the sire producing immature or aged spermatozoa. The observation that fertility increases as the number of sires contributing to the inseminate increases (Beatty, 1960) could be explained on the basis that increasing the number of sires, and so the number of different rates of sperm maturation, also increases the chances of the presence of optimally mature spermatozoa at the time of ovulation. This may explain the shift in predominance shown in Table 2 where $W$ was predominant in Groups 1, 2 , and 3 but was subordinate in Group 4 when the $W$ spermatozoa were stored in M. Unpublished evidence (Graves, 1970) using fresh semen from the same males as were used in this experiment showed that $\mathrm{B}$ was predominant to $\mathrm{W}$ in the ratio of $85: 15$. Roche et al. (1968) also found that the heterospermically predominant sire lost his predominance when spermatozoa from both males were stored in vitro for $24 \mathrm{hr}$. A hypothesis to explain the observations is proposed in Text-fig. 1. The subminimal relative fertility represented by the lines at the time before ejaculation is based on our interpretation of the data of Orgebin-Crist (1968). The positions of the lines representing the different male-extender combinations near 12 and $36 \mathrm{hr}$ after ejaculation are based on our interpretation of previous observations in these laboratories using in some cases the same males, but in all cases the same system (Graves, unpublished data; Roche et al., 1968). The evidence at $60 \mathrm{hr}$ is from the present experiment. Lines connecting these points are interpolations. Spermatozoa increase in maturity and fertilizing ability as they pass through the epididymis and spend time in the female reproductive tract and then lose fertilizing ability as they age. The spermatozoa from $W$ males may be ejaculated in a less mature state and may then mature more slowly than the spermatozoa from B males. When 
semen is stored in $\mathrm{M}$, the rate of ageing is accelerated, therefore at the time of fertilization, near $58 \mathrm{hr}$ after ejaculation, spermatozoa from the different males are at different stages of maturity. This demonstrates that when comparisons are made between males or between semen treatments, spermatozoa must be of the same chronological age at the time of fertilization in order to reach valid conclusions. This applies to homospermic as well as heterospermic inseminations and may account for the variability found when attempting to make comparisons from homospermic inseminations.

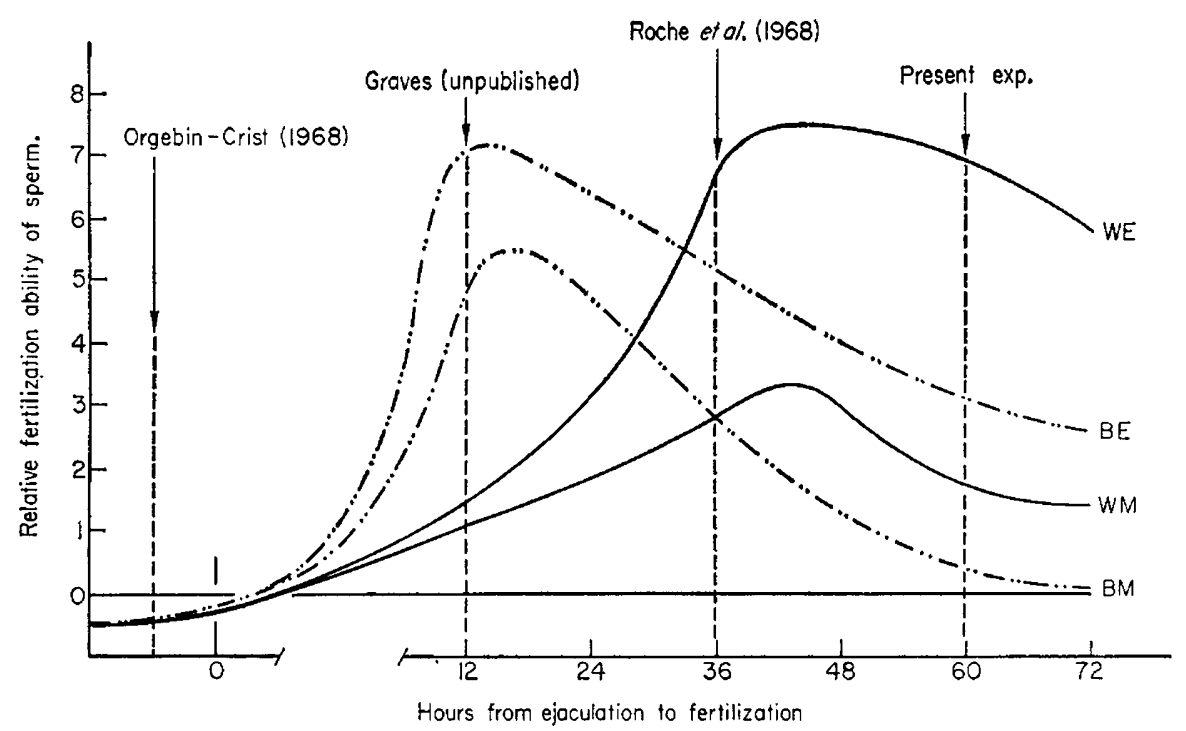

TEXT-FIG. 1. Hypothesis for the relative fertilizing ability of spermatozoa of different males after storage in two extenders for varying periods. $\mathrm{B}=$ Black male; $\mathrm{W}=$ White male; $\mathbf{E}=$ Egg extender; $\mathbf{M}=$ Milk extender.

\section{AGKNOWLEDGMENTS}

The authors are grateful to Dr H. W. Norton and Dr R. H. Foote for advice and information on statistical interpretation.

\section{REFERENCES}

Beatty, R. A. (1957) A pilot experiment with heterospermic insemination in the rabbit. F. Genet. 55, 325.

BeAtTy, R. A. (1960) Fertility of mixed semen from different rabbits. F. Reprod. Fert. 1, 52.

Beatty, R. A., Bennett, G. H., Hall, J. G., Hancock, J. L. \& Stewart, D. L. (1969) An experiment with heterospermic insemination in cattle. F. Reprod. Fert. 19, 491.

Dunn, H. O., Henderson, C. R. \& Godrrey, J. T. (1956) The use of estimated variance components in design of fertility experiments with bovine semen. Anim. Sti. 15, 1222.

Dzruk, P. J. (1965) Double mating of rabbits to determine capacitation time. F. Reprod. Fert. 10, 389.

Dzıuk, P. J. (1970) Estimation of optimum time for insemination of gilts and ewes by double mating at certain times relative to ovulation. $\mathcal{F}$. Reprod. Fert. 22, 277.

EDWARDs, R. G. (1955) Selective fertilization following the use of sperm mixtures in the mouse. Nature, Lond. 175, 215.

Miller, O. G., Roche, J. F. \& Dziur, P. J. (1969) Estimation of the optimum interval between insemination and ovulation in the rabbit by double insemination. F. Reprod. Fert. 19, 545. 
ORGEBIN-CRIST, M. C. (1968) Maturation of spermatozoa in the rabbit epididymis: delayed fertilization in does inseminated with epididymal spermatozoa. F. Reprod. Fert. 16, 29.

Roche, J. F., DzIUK, P. J. \& LODGE, J. R. (1968) Competition between fresh and aged spermatozoa in fertilizing rabbit eggs. F. Reprod. Fert. 16, 155.

Salisbury, G. W. (1965) Aging phenomena in gametes. F. Geront. 20, 281.

Salisbury, G. W. \& VANDemark, N. L. (1961) Physiology of reproduction and artificial insemination of cattle, pp. 473-849. Freeman, San Francisco and London.

VanDemark, N. L. \& Sharma, U. D. (1957) Preliminary fertility results from the preservation of bovine semen at room temperatures. F. Dairy Sci. 40, 438. 